\title{
Anti-Inflammatory Effects of Moxibustion on Mice with Adjuvant Arthritis: Role of TRPV1
}

\author{
Jie-Jun Li, Jin-Feng Jiang ${ }^{*}$, Ying Jiang and Xiao-Jing Wu
}

Key Laboratory of Acupuncture Combined with Medication, The Second Clinical Medical College, Nanjing University of Traditional Chinese Medicine, Nanjing 210046, China

"Corresponding author: Jin-feng Jiang. Institutional addresses:Key Laboratory of Acupuncture Combined with Medication, The Second Clinical Medical College, Nanjing University of Traditional Chinese Medicine, Nanjing 210046, China, Tel: +86-13951717991; E-mail: Dr. acujf@njutcm. edu. cn

Received date: August 26, 2015, Accepted date: October 9, 2015, Published date: October 16, 2015

Copyright: ( 2015 , Li JJ, et al. This is an open-access article distributed under the terms of the Creative Commons Attribution License, which permits unrestricted use, distribution, and reproduction in any medium, provided the original author and source are credited.

\begin{abstract}
Aim and Objective: This research was done to observe the anti-inflammatory effect of moxibustion and explore the role of Transient Receptor Potential Vanilloid sub type 1 (TRPV1) on Mice with adjuvant arthritis.

Method: Adjuvant arthritis (AA) was established by using the amount of $20 \mu \mathrm{L}$ of Freund's Adjuvant Complete (FCA) intradermal injected into right hindfoot plantar. $50 \mathrm{KM}$ mice were randomized into 6 groups by random number table method: control group $(n=10)$, model group $(n=8)$, capsaicin group $(n=8)$, capsazepine group $(n=8)$, moxibustion group $(n=8)$ and Moxibustion+Capsazepine (MC) group $(n=8)$. 16 C57BL/6 wild-type mice are randomized into 2 groups by random number table method: Wild-Type (WT) model group and WT moxibustion group with 8 in each. 14 TRPV1 knockout mice are randomized into 2 groups by random number table method: knockout (KO) model group and KO moxibustion group with 7 in each.
\end{abstract}

Each mouse in the capsaicin group is subcutaneously injected with the amount of $0.1 \mathrm{ml} / 10 \mathrm{~g}$ into the L5, L6 spinal cords. Each mouse in the capsazepine group was intraperitoneally injected with the amount of $0.1 \mathrm{ml} / 10 \mathrm{~g}$. Similarly, each mouse in the moxibustion group, WT moxibustion group and KO moxibustion group was given a suspended moxibustion with $5 \mathrm{~mm} \times 200 \mathrm{~mm}$ specially-made moxa stick for 20 minutes on L5 and L6 spinal cords. Kept the distance between the moxa stick and the skin where L5 and L6 spinal cords located was $10 \pm 2 \mathrm{~mm}$ that the temperature was stabilized at $46 \pm 1{ }^{\circ} \mathrm{C}$. Each mouse in $\mathrm{MC}$ group was intraperitoneally injected with the amount of $0.1 \mathrm{ml} / 10 \mathrm{~g}$ first, then after 15 minutes was given a suspended moxibustion for 20 minutes on L5 and L6 spinal cords.

All the treatments above were performed at the same day when models were successfully establishedand performed once per day for 7 days in total. During the performance, mice in the control group, model group, WT model group and KO model group were of no treatment in any way. The right hindfoot paw volumes of mice in each group were measured and recorded on Day 1, Day 2, Day 4, Day 6 and Day 8 of the experiment. After all treatments, the serum IL-1 $\beta$ and TNF- $\alpha$ level was determined by ELISA.

Results: Compared with the model group, the paw volumes in the moxibustion group was significantly decreased $(P<0.01)$, simultaneously moxibustion caused a significant decrease in serum IL-1 $\beta$ and TNF- $\alpha$ levels $(P<0.01)$. Compared with the model group, the paw volumes, serum IL-1 $\beta$ and TNF- $\alpha$ levels in the Moxibustion+Capsazepine (MC) group was significantly decreased $(P<0.01)$; but compared with moxibustion group, the paw volumes, serum IL-1 $\beta$ and TNF- $\alpha$ levels in MC group was obviously increased with significance in between $(P<0.05)$. Compared with $\mathrm{KO}$ control group, no changes in the paw volumes, serum IL-1 $\beta$ and TNF- $\alpha$ levels in KO moxibustion group, there was no significant difference in between $(P>0.05)$.

Conclusions: TRPV1 plays a central role in the anti-inflammatory effect of moxibustion, while the effect may be lost if lacked of TRPV1-mediated.

\section{Keywords: TRPV1; Moxibustion; Inflammation}

\section{Introduction}

Moxibustion, one of tranditional Chinese medicine therapies, stimulates the body mainly in a warm/heat manner by burning moxa to alter local temperature and to activate cutaneous thermoreceptors, and thus produces its curative effect. Researchers have pointed out that the thermal stimulation is an important determination of the therapeutic efficacy of moxibustion [1]. It has been demonstrated that moxibustion of $46^{\circ} \mathrm{Cdramatically} \mathrm{lowered} \mathrm{cholesterol} \mathrm{in} \mathrm{a} \mathrm{mice} \mathrm{model}$ of acute hyperlipidemia, better than that of $38^{\circ} \mathrm{C}$, indicating temperature plays a critical role in the effect of moxibustion therapy [2]. Furthermore, investigators showed there was no significant difference on the effect between medicinal cake-separated and paper pad-separated moxibustion in wheat-grain size cone moxibustion groups, implying the temperature is essential to therapeutic effect of moxibustion. 
Transient receptor potential vanilloid subtype 1 (TRPV1), a heat thermoreceptor discovered in recent years, is expressed on terminals of small and medium-sized primary sensory neurons in both peripheral and central nervous system [3]. The thermal activation threshold of TRPV1 is higher than $43^{\circ} \mathrm{C}$ [4] and equal to the temperature of the local skin stimulated by moxibustion. The peak value of skin temperature ranged from $45.2^{\circ} \mathrm{C}$ to $45.5^{\circ} \mathrm{C}$ in ginger-separated, direct and suspended moxibustion [5]. In moxibustion applying moxibustion-box, the skin temperature averaged above $44^{\circ} \mathrm{C}$ when the distance was $4 \mathrm{~cm}$, while ranged from $44^{\circ} \mathrm{C}$ to $49^{\circ} \mathrm{C}$ when the distance was $3 \mathrm{~cm}$.

Furthermore, the animal experiments [2] showed that when the distance between the skin and the moxa stick was $35 \pm 5 \mathrm{~mm}$, the temperature was stabilized at $38 \pm 1^{\circ} \mathrm{C}$; when the distance was $10 \pm 2$ $\mathrm{mm}$, the temperature was stabilized at $46 \pm 1^{\circ} \mathrm{C}$. TRPV1 was recognized as one of the thermo-sensitive cation channels [6], and such characteristic determined its necessary correlation with the therapeutic effects of moxibustion.

Inflammatory responses have been implicated in most of diseases [1], it is the main pathological basis of the therapeutic effects of moxibustion. It is universial that anti-inflammatory therapeutic effect of moxibustion is aimed at reversing the dysfunction state of inflammatory response. The universial effect is the basis of extensive clinical therapeutic function of moxibustion, which is manifested in many indications of moxibustion, including disorders of nervous, digestive, cardiocerebral vascular, and the endocrinium system, as well as the infectious diseases and tumour. It has been showed that the disease spectrum of moxibustion covered such as diarrhea, colitis, dysmenorrhea, osteoarthritis, soft tissue injury, asthma, uroschesis and herpes zoster.

Furthermore, there were studies demonstrated that long snake moxibustion can effectively relieve clinical symptoms of ankylosing spondylitis [7], while significantly downsrend I-CAM1 and TNF-a, regulating and controlling the inflammatory response. Moxibustion could up-regulate TGF- $\alpha$ contents expression in gastric mucosa lesion rats [8]. Atherosclerosis (AS) is a chronic inflammatory disease. Animal experiments found that moxibustion significantly decreased the levels of IL-6, IL- 8 and TNF- $\alpha$ in chronic hyperlipidemic rats, indicating that moxibustion can effectively suppress inflammation while regulating the blood lipids [9]. Another research showed that the IL- $1 \beta$ and TNF- $\alpha$ levels in the synovial fluid of RA rabbits could be inhibited by moxibustion [10].

It has been proved that TRPV1 act as an important site of antiinflammation and analgesia. Studies found that TRPV1 knockout mice showed enhanced LPS-induced sepsis compared with wild type [11-13]; what's more, TRPV1 showed protective effects in the inflammatory disorders of cardiovascular [12]. All of these evidences certify that TRPV1 acts to protect against the damaging impact of dieases and may influence the transition from local to a systemic inflammatory state [13].

Studies suggested administration of a TRPV1 agonist resiniferatoxin decreased TNF- $\alpha$ levels, and significantly attenuated the development of thermal hyperalgesia in the Streptozotocin-induced diabetes model [14]. Furthermore, application of capsaicin effectively suppressed the expression of COX-2 and mPGES-1 mRNAs, so as to attenuate the inflammatory osteoporosis and inhibit bone resorption induced by lipopolysaccharide [15].
The study was designed to study the role of TRPV1 in the antiinflammatory effects of moxibustion. The anti-inflammatory effect of moxibustion relies on the heat stimulation; TRPV1 is an important target of anti-inflammation and analgesia, and application of TRPV1 agonists has anti-inflammatory effects; noxious heat is one of TRPV1 activators; heat stimulation higher than $43^{\circ} \mathrm{C}$ is in the range of the skin temperature produced by moxibustion clinically, which is equal to TRPV1 activation temperature threshold. Therefore, we made a hypothesis that TRPV1 played a central role in the anti-inflammatory effect on moxibustion. Without TRPV1 mediating, moxibustion may lose its anti-inflammatory effect.

\section{Materials and Methods}

\section{Experimental animals}

50 Kunming (KM) male mice of 32-36 g (Certificate No. of SCXK (Shanghai): 2007-0005, provided by Shanghai Slac Laboratory Animal Co., Ltd.), 16 C57BL/6 wild-type male mice of 16-20 g (Certificate No. of SCXK (Jiangsu): 2010-0001, provided by Laboratory Animal Center of Nanjing University), and 14 J003770 TRPV1 knockout male mice of 17-20 g (Certificate No. SCXK (Jiangsu): 2010-0001, provided by Laboratory Animal Center of Nanjing University). All the animals were maintained in the SPF Experimental Animals Center of Nanjing University of Chinese Medicine. Use of animals was in accordance with the Guidelines to Treat the Experimental Animals published by the Ministry of Science and Technology of People's Republic of China [16].

\section{Reagent preparation}

Freund's Adjuvant, Complete (FCA) [10 ml] Capsaicin [50 mg] Capsazepine [25 mg] $500 \mathrm{ml}$ absolute ethyl alcohol, Polyoxyethylene Sorbitan (Tween 80$)$ [500 ml] and Dimethyl Sulfoxide [50 ml] were purchased from Sigma (St. Louis, MO, USA). Normal Saline [250 ml] was purchased from Guangdong Litai pharmaceutical Limited by Share Ltd (Guangdong, China). Capsaicin in powder $50 \mathrm{mg}$ is dissolved in $10 \%$ polyoxyethylene sorbitan (Tween 80 ) and $10 \%$ ethanol before being mixed with $80 \%$ normal saline to obtain a capsaicin solution of $0.01 \mathrm{M}$ [11] ; Capsazepine in powder $25 \mathrm{mg}$ is dissolved in $25 \mathrm{ml}$ dimethyl sulphoxide and then diluted in normal saline to obtain a capsazepine solution of $0.01 \mathrm{M}$ [17].

\section{Major experimental instruments}

Paw Volume Measuring Instrument (YLS-7B, Ji Nan Yi Yan TechnologyCo., Ltd., Jinan, China), Special Moxa Stick $(5 \mathrm{~mm} \times 200$ mm, Nanyang Chinese herbal medicine Co., Ltd., Nanyang, China), 1 $\mathrm{ml}$ Disposable Sterile Syringe (Changzhou medical equipment General Factory Co., Ltd., Changzhou, China), Micro Syringe (25 $\mu \mathrm{L}$, Shanghai Precision Instrument Co., Ltd., Shanghai, China).

\section{Experimental methods}

Grouping: A total of $50 \mathrm{KM}$ mice $(20 \pm 2 \mathrm{~g})$ were randomized into 6 groups by random number table method: control group $(n=10)$, model group $(n=8)$, capsaicin (Cap) group $(n=8)$, capsazepine (Cpz) group $(n=8)$, moxibustion (Mox) group $(n=8)$ and moxibustion+capsazepine (MC) group $(\mathrm{n}=8)$.

A total of $16 \mathrm{C} 57 \mathrm{BL} / 6$ wild-type mice $(18 \pm 2 \mathrm{~g})$ are randomized into 2 groups by random number table method: wild-type (WT) model group and WT moxibustion group with 8 in each. Similarly, a total of 
14TRPV1 knockout mice ( $18 \pm 2 \mathrm{~g})$ are randomized into 2 groups by random number table method: knockout $(\mathrm{KO})$ model group and $\mathrm{KO}$ moxibustion group with 7 in each. Basic values of the right hindfoot paw volume of each mouse was measured and recorded.

Model establishing: Except the control group, each mouse in the other groups was intradermal injected with the amount of $20 \mu \mathrm{L}$ of Freund's Adjuvant Complete (FCA) into right hindfoot plantar, and was observed the changes of mice paw joints.

After $24 \mathrm{~h}$, the right hindfoot paw volumes of all the mice were measured and recorded by paw volume measuring instrument. According to the assessment of arthritis index score table $>4$ points, showing the adjuvant arthritis model in mice was successed.

Group treatments: Hair located $1 \mathrm{~cm} \times 2 \mathrm{~cm}$ around the L5, L6 spinal cords [18] of the mice in the moxibustion group, MC group, WT moxibustion group and $\mathrm{KO}$ moxibustion group was cut of to expose the skin which was then disinfected by alcohol tampon. Each mouse in the capsaicin group is subcutaneously injected with the amount of 0.1 $\mathrm{ml} / 10 \mathrm{~g}$ into the L5, L6 spinal cords.

Each mouse in the capsazepine group was intraperitoneally injected with the amount of $0.1 \mathrm{ml} / 10 \mathrm{~g}$. Similarly, each mouse in the moxibustion group, WT moxibustion group and $\mathrm{KO}$ moxibustion group was given a suspended moxibustion with specially-made moxa stick for 20 minutes on L5 and L6 spinal cords.

Kept the distance between the moxa stick and the skin where L5 and L6 spinal cords located was $10 \pm 2 \mathrm{~mm}$ [2]. Each mouse in MC group was intraperitoneally injected with the amount of $0.1 \mathrm{ml} / 10 \mathrm{~g}$ first, then after 15 minutes was given a suspended moxibustion for 20 minutes on L5 and L6 spinal cords.

All the treatments above were performed at the same day when models were successfully established and performed once per day for 7 days in total. During the performance, mice in the control group, model group, WT model group and $\mathrm{KO}$ model group were of no treatment in any way.

Materials: On the last day of the experiment, blood samples were taken by excising the eyeballs. Serum was extracted by centrifuging at $3000 \mathrm{r} / \mathrm{min}$ for $15 \mathrm{~min}$. The supernatant was collected into a $0.5 \mathrm{~mL}$ Eppendorf tube and then stored at $-20^{\circ} \mathrm{C}$ for later uses.

Indexes detection: Paw Volumes Measurement: The right hind foot paw volumes of mice in each group were measured and recorded on Day 1, Day 2, Day 4, Day 6 and Day 8 of the experiment. Serum Testing: Serum samples were sent to Nanjing KeyGen Biotech. Co., Ltd where the serum IL- $1 \beta$ and TNF- $\alpha$ level was determined by ELISA.

Statistics and analysis of datas: All data's are presented as mean \pm standard deviation statistics, tested by One-Way ANOVA analysis with SPSS17.0 (SPSS, Chicago, IL, USA), and 'p' values less than 005 were accepted as indicating significant differences for group-group comparisons.

\section{Results}

\section{Effect of moxibustion on AA}

As shown in Tables 1, 2, Figures 1 and 2, on the eighth day, compared with the model group, the paw volumes in the capsaicin group and moxibustion group were significantly decreased $(\mathrm{P}<0.01)$. the serum IL- $1 \beta$ and TNF- $\alpha$ levels in the capsaicin group and moxibustion group were significantly decreased $(\mathrm{P}<0.01)$. Compared with the moxibustion group, the paw volume, the serum IL- $1 \beta$ and TNF- $\alpha$ levels in capsaicin group were obviously increased with significance in between $(\mathrm{P}<0.01)$.

\begin{tabular}{|c|c|c|c|c|c|}
\hline & Day 1 & Day 2 & Day 4 & Day 6 & Day 8 \\
\hline $\begin{array}{l}\text { Control } \\
\text { group }\end{array}$ & $\begin{array}{l}0.255 \\
\pm \\
0.016\end{array}$ & $\begin{array}{l}0.272 \quad \pm \\
0.015\end{array}$ & $\begin{array}{l}0.286 \\
0.025\end{array}$ & $\begin{array}{l}0.282 \\
0.039\end{array}$ & $0.280 \pm 0.022$ \\
\hline $\begin{array}{l}\text { Model } \\
\text { group }\end{array}$ & $\begin{array}{l}0.254 \\
\pm \\
0.031\end{array}$ & $\begin{array}{l}0.489 \\
0.022\end{array} \quad \pm$ & $\begin{array}{ll}0.507 & \pm \\
0.036 \wedge \Delta & \end{array}$ & $\begin{array}{ll}0.443 & \pm \\
0.031 \wedge \Delta & \pm\end{array}$ & $\begin{array}{l}0.429 \\
0.028 \Delta \wedge\end{array}$ \\
\hline $\begin{array}{l}\text { Cap } \\
\text { group }\end{array}$ & $\begin{array}{l}0.285 \\
\pm \\
0.016\end{array}$ & $\begin{array}{l}0.485 \leq \pm \\
0.022 \wedge \boldsymbol{\Delta}\end{array}$ & $\begin{array}{l}0.402 \\
0.022 \Delta \Delta^{* *}\end{array} \pm$ & $\begin{array}{l}0.406 \\
0.034 \wedge \Delta\end{array}$ & $\begin{array}{l}0.363 \\
0.019^{\wedge} \mathbf{\Lambda}^{* *} \# \#\end{array}$ \\
\hline $\begin{array}{l}\text { Mox } \\
\text { group }\end{array}$ & $\begin{array}{l}0.273 \\
\pm \\
0.024\end{array}$ & $\begin{array}{l}0.486 \_ \pm \\
0.041 \wedge \Delta\end{array}$ & $\begin{array}{l}0.409 \\
0.065^{\wedge} \Delta^{* *}\end{array}$ & $\begin{array}{l}0.388 \\
0.031 \wedge \wedge^{* *}\end{array}$ & $\begin{array}{l}0.323 \\
0.043^{\Delta} \Delta^{* *}\end{array}$ \\
\hline
\end{tabular}

Notice: Control and Model: no treatment; Cpsaicin: subcutaneous injection with the amount of $0.1 \mathrm{ml} / 10 \mathrm{~g}$ capsaicin into the L5-L6 segment; Moxibustion: a suspended moxibustion with a specially-made moxa stick for 20 minutes on L5L6 segment. Compared with the control group, $\Delta \mathrm{P}<0.05, \Delta \Delta^{\Delta}<0.01$; Compared with the model group, ${ }^{*} \mathrm{P}<0.05,{ }^{* *} \mathrm{P}<0.01$; compared with the moxibustion group, ${ }^{\mathrm{P}}<0.05,{ }^{\# \#} \mathrm{P}<0.01$.

Table 1: Comparisons of paw volumes in each group (ml).

\begin{tabular}{|c|c|c|c|c|c|c|c|}
\hline & $\begin{array}{l}\text { Control } \\
\text { group }\end{array}$ & $\begin{array}{l}\text { Model } \\
\text { group }\end{array}$ & & Cap group & & Mox group & \\
\hline IL-1 $\beta$ & $31.39 \pm 1.86$ & $\begin{array}{l}83.45 \\
8.61 \wedge \Delta\end{array}$ & & $\begin{array}{l}47.76 \\
2.22^{\mathbf{\Lambda}} \mathbf{\Delta}^{\star \star} \# \#\end{array}$ & \pm & $\begin{array}{l}34.65 \\
3.74^{\mathbf{4}}\end{array}$ & \pm \\
\hline TNF- $\alpha$ & $24.82 \pm 1.65$ & $\begin{array}{l}66.29 \\
3.44 \mathbf{\Lambda}\end{array}$ & & $\begin{array}{l}36.01 \\
1.31^{\wedge} \mathbf{\Delta}^{\star \star} \# \#\end{array}$ & \pm & $\begin{array}{l}31.00 \\
1.22^{\mathbf{\Delta}} \mathbf{4}^{* *}\end{array}$ & \pm \\
\hline
\end{tabular}

Notice: Control and Model: no treatment; Cpsaicin: subcutaneous injection with the amount of $0.1 \mathrm{ml} / 10 \mathrm{~g}$ capsaicin into the L5-L6 segment; Moxibustion: a suspended moxibustion with a specially-made moxa stick for 20 minutes on L5L6 segment. Compared with the control group, $\Delta \mathrm{P}<0.05, \Delta \mathbf{\Delta} \mathrm{P}<0.01$; Compared with the model group, ${ }^{*} \mathrm{P}<0.05,{ }^{* *} \mathrm{P}<0.01$; compared with the moxibustion group, ${ }^{\#} \mathrm{P}<0.05,{ }^{\# \#} \mathrm{P}<0.01$.

Table 2: Comparisons of inflammatory factors in each group ( $\mathrm{pg} / \mathrm{ml})$.

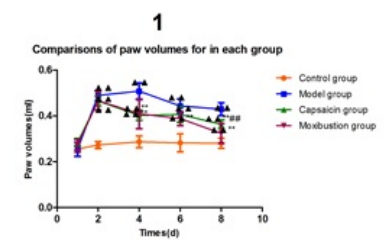

Figure 1: Data of inflammatory factors were presented as mean \pm SEM $(n=8)$ by histogram. Control and model group were of no treatment; capsaicin group was treated with subcutaneous injection of $0.1 \mathrm{ml} / 10 \mathrm{~g}$ capsaicin into the L5-L6 segment; moxibustion group was given a suspended moxibustion with a specially-made moxa stick for 20 minutes on L5-L6 segment. Data of paw volumes were presented as mean \pm SEM $(n=8)$ by curve graph. 
Page 4 of 8

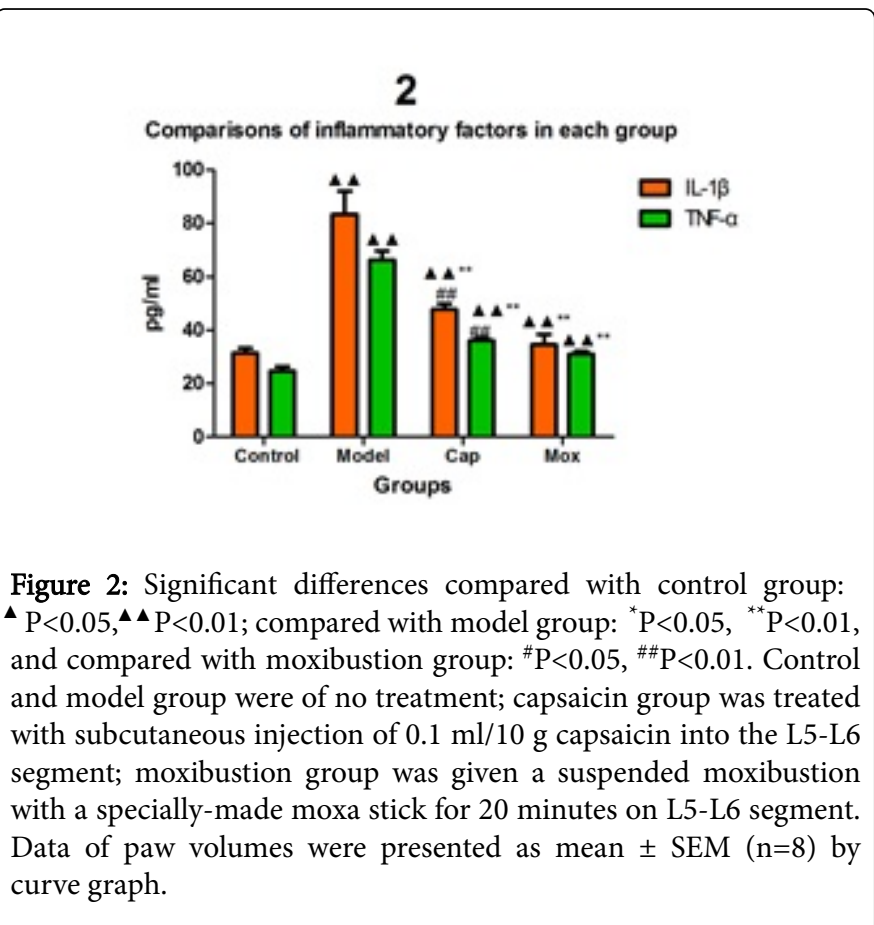

\section{Effect of moxibustion on AA after pretreatment by capsazepine}

As shown in Tables 3, 4, Figures 3 and 4, compared with the model group, the paw volumes, the serum IL- $1 \beta$ and TNF- $\alpha$ levels in the capsazepine group, moxibustion group and MC group were significantly decreased $(\mathrm{P}<0.01)$.

Compared with the moxibustion group, the paw volumes, the serum IL- $1 \beta$ and TNF- $\alpha$ levels in MC group was obviously increased with significance in between $(\mathrm{P}<0.01)$.

\begin{tabular}{|c|c|c|c|c|c|}
\hline & Day 1 & Day 2 & Day 4 & Day 6 & Day 8 \\
\hline $\begin{array}{l}\text { Control } \\
\text { group }\end{array}$ & $\begin{array}{l}0.255 \pm \\
0.016\end{array}$ & $\begin{array}{l}0.272 \\
0.015\end{array}$ & $\begin{array}{l}0.286 \\
0.025\end{array}$ & $\begin{array}{l}0.282 \\
0.039\end{array}$ & $\begin{array}{l}0.280 \\
0.022\end{array}$ \\
\hline $\begin{array}{l}\text { Model } \\
\text { group }\end{array}$ & $\begin{array}{l}0.254 \pm \\
0.031\end{array}$ & $\begin{array}{l}0.489 \_ \pm \\
0.022 \Delta \wedge\end{array}$ & $\begin{array}{ll}0.507 & \pm \\
0.036 \wedge \Delta & \end{array}$ & $\begin{array}{ll}0.443 & \pm \\
0.031 \wedge \Delta & \end{array}$ & $\begin{array}{ll}0.429 & \pm \\
0.028 \Delta \wedge & \end{array}$ \\
\hline $\begin{array}{l}\text { Cpz } \\
\text { group }\end{array}$ & $\begin{array}{l}0.269 \pm \\
0.034\end{array}$ & 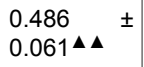 & $\begin{array}{l}0.396 \\
0.043^{\wedge} \Delta^{* *}\end{array}$ & $\begin{array}{ll}0.411 & \pm \\
0.036 \wedge \Delta & \pm\end{array}$ & $\begin{array}{l}0.343 \\
0.022 \boldsymbol{\Delta} \boldsymbol{\Delta}^{* *}\end{array}$ \\
\hline $\begin{array}{l}\text { Mox } \\
\text { group }\end{array}$ & $\begin{array}{l}0.273 \pm \\
0.024\end{array}$ & $\begin{array}{l}0.486 \_ \pm \\
0.041 \wedge \Delta\end{array}$ & $\begin{array}{l}0.409 \\
0.065^{\wedge} \Lambda^{* *}\end{array}$ & $\begin{array}{l}0.388 \quad \pm \\
0.031 \Delta \Delta^{* *}\end{array}$ & $\begin{array}{l}0.323 \\
0.043 \Delta \Delta^{\star * *}\end{array}$ \\
\hline MC group & $\begin{array}{l}0.296 \pm \\
0.020\end{array}$ & $\begin{array}{l}0.489 \\
0.030^{\Delta \wedge}\end{array} \quad \pm$ & $\begin{array}{l}0.440 \\
0.015^{\wedge} \Lambda^{\star *}\end{array}$ & $\begin{array}{l}0.400 \\
0.031 \Delta \Lambda^{*}\end{array}$ & $\begin{array}{l}0.354 \\
0.023 \Delta \Delta^{\star *} \#\end{array}$ \\
\hline
\end{tabular}

Notice: Control and Model: no treatment; Capsazepine: intraperitoneal injection with the amount of $0.1 \mathrm{ml} / 10 \mathrm{~g}$ capsazepine; Moxibustion: a suspended moxibustion with a specially-made moxa stick for 20 minutes on L5 and L6 spinal cords; MC: intraperitoneal injection with the amount of $0.1 \mathrm{ml} / 10 \mathrm{~g}$ capsazepine first, and then a suspended moxibustion for 20 min on L5-L6 segment after a $15 \mathrm{~min}$ interval. Compared with the control group, $\Delta \mathrm{P}<0.05$, $\triangle \triangle P<0.01$; Compared with the model group, ${ }^{*} P<0.05$, ${ }^{* *} P<0.01$; compared with the moxibustion group, $\# \mathrm{P}<0.05, \# \# \mathrm{P}<0.01$.

Table 3: Comparisons of paw volumes in each group (ml).

\begin{tabular}{|c|c|c|c|c|c|}
\hline & $\begin{array}{l}\text { Control } \\
\text { group }\end{array}$ & $\begin{array}{l}\text { Model } \\
\text { group }\end{array}$ & Cpz group & Mox group & MC group \\
\hline IL-1 $\beta$ & $\begin{array}{l}31.39 \quad \pm \\
1.86\end{array}$ & $\begin{array}{l}83.45 \wedge \pm \\
8.61 \wedge \Delta\end{array}$ & $\begin{array}{l}50.55 \quad \pm \\
1.27 \Delta \mathbf{\Delta}^{* *} \# \#\end{array}$ & $\begin{array}{ll}34.65 & \pm \\
3.74 \boldsymbol{\Lambda} \Delta^{*} *\end{array}$ & $\begin{array}{l}71.02 \\
1.85^{\mathbf{\Delta}} \mathbf{\Delta}^{* * \# \#} \quad \pm\end{array}$ \\
\hline TNF- $\alpha$ & $\begin{array}{l}24.82 \quad \pm \\
1.65\end{array}$ & $\begin{array}{l}66.29 \wedge \pm \\
3.44 \wedge \backslash\end{array}$ & $\begin{array}{l}37.18 \quad \pm \\
1.08^{\mathbf{\Lambda}} \mathbf{\Delta}^{* *} \#^{ \pm}\end{array}$ & $\begin{array}{l}31.00 \\
1.22^{\mathbf{\Lambda}} \mathbf{\Lambda}^{* *}\end{array}$ & 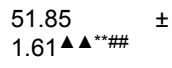 \\
\hline
\end{tabular}

Notice: Control and Model: no treatment; Capsazepine: intraperitoneal injection with the amount of $0.1 \mathrm{ml} / 10 \mathrm{~g}$ capsazepine; Moxibustion: a suspended moxibustion with a specially-made moxa stick for 20 minutes on L5 and L6 spinal cords; MC: intraperitoneal injection with the amount of $0.1 \mathrm{ml} / 10 \mathrm{~g}$ capsazepine first, and then a suspended moxibustion for 20 min on L5-L6 segment after a $15 \mathrm{~min}$ interval. Compared with the control group, $\mathbf{\Delta} \mathrm{P}<0.05$, $\triangle \Delta \mathrm{P}<0.01$; Compared with the model group, ${ }^{*} \mathrm{P}<0.05$, ${ }^{* *} \mathrm{P}<0.01$; compared with the moxibustion group, ${ }^{\#} \mathrm{P}<0.05$, ${ }^{\#} \mathrm{P}<0.01$

Table 4: Comparisons of inflammatory factors in each group (pg/ml).

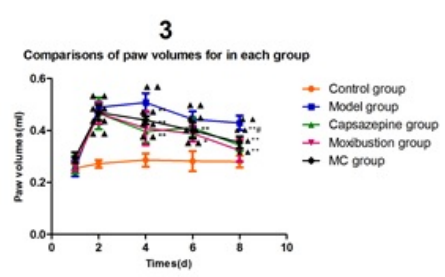

Figure 3: Data of inflammatory factors were presented as mean \pm SEM $(n=8)$ by histogram. Control and Model group: no treatment; Capsazepine: intraperitoneal injection with the amount of $0.1 \mathrm{ml} / 10$ g; Moxibustion: a suspended moxibustion with specially-made moxa stick for 20 minutes on L5 and L6 spinal cords; MC: intraperitoneal injection with the amount of $0.1 \mathrm{ml} / 10 \mathrm{~g}$ capsazepine first, and then a suspended moxibustion for $20 \mathrm{~min}$ on L5-L6 segment after a 15 min interval. Data of paw volumes were presented as mean \pm SEM $(n=8)$ by curve graph.

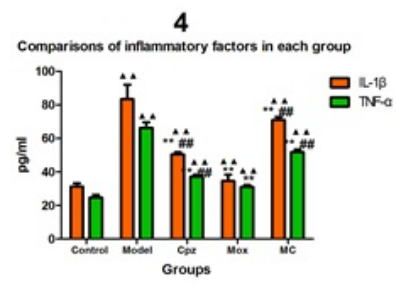

Figure 4: Significant differences compared with control group: $\triangle \mathrm{P}<0.05, \Delta \mathbf{\Delta}<0.01$; compare with model group: ${ }^{*} \mathrm{P}<0.05,{ }^{* *} \mathrm{P}<0.01$, and compared with moxibustion group : ${ }^{\#} \mathrm{P}<0.05,{ }^{\# \#} \mathrm{P}<0.01$. Control and Model group: no treatment; Capsazepine: intraperitoneal injection with the amount of $0.1 \mathrm{ml} / 10 \mathrm{~g}$; Moxibustion: a suspended moxibustion with specially-made moxa stick for 20 minutes on L5 and L6 spinal cords; MC: intraperitoneal injection with the amount of $0.1 \mathrm{ml} / 10 \mathrm{~g}$ capsazepine first, and then a suspended moxibustion for 20 min on L5-L6 segment after a 15 min interval. Data of paw volumes were presented as mean $\pm \operatorname{SEM}(n=8)$ by curve graph. 
Page 5 of 8

\section{Effect of moxibustion on AA in wild-type groups and TRPV1 knockout groups}

As shown in Tables 5, 6, Figures 5 and 6, compared with WT model group, on the eighth day, the paw volumes, the serum IL- $1 \beta$ and TNFa levels in WT moxibustion group had been decreased significantly $(\mathrm{P}<0.01)$; compared with $\mathrm{KO}$ model group, no changes in the paw volumes, the serum IL-1 $\beta$ and TNF- $\alpha$ levels in KO moxibustion group, there were no significant difference in between $(\mathrm{P}>0.05)$.

\begin{tabular}{|c|c|c|c|c|c|c|}
\hline & Day 1 & Day 2 & Day 4 & Day 6 & Day 8 & \\
\hline $\begin{array}{l}\text { WT model } \\
\text { group }\end{array}$ & $\begin{array}{l}0.171 \\
0.012\end{array}$ & $\begin{array}{l}0.256 \quad \pm \\
0.014\end{array}$ & $\begin{array}{ll}0.262 & \pm \\
0.018 & \end{array}$ & $\begin{array}{l}0.311 \\
0.029\end{array} \quad \pm$ & $\begin{array}{l}0.302 \\
0.016\end{array}$ & \pm \\
\hline $\begin{array}{l}\text { WT } \operatorname{mox} \\
\text { group }\end{array}$ & $\begin{array}{l}0.177 \\
0.010\end{array}$ & $\begin{array}{l}0.250 \\
0.019\end{array}$ & $\begin{array}{l}0.253 \\
0.019\end{array}$ & $\begin{array}{l}0.286 \\
0.014\end{array}$ & $\begin{array}{l}0.259 \\
0.017^{* *}\end{array}$ & \pm \\
\hline $\begin{array}{l}\text { KO model } \\
\text { group }\end{array}$ & $\begin{array}{l}0.153 \quad \pm \\
0.011\end{array}$ & $\begin{array}{l}0.283 \quad \pm \\
0.016\end{array}$ & $\begin{array}{l}0.280 \\
0.015\end{array}$ & $\begin{array}{l}0.290 \\
0.025\end{array}$ & $\begin{array}{l}0.292 \\
0.003\end{array}$ & \pm \\
\hline $\begin{array}{l}\text { KO mox } \\
\text { group }\end{array}$ & $\begin{array}{l}0.159 \\
0.008\end{array}$ & $\begin{array}{l}0.287 \\
0.033\end{array}$ & $\begin{array}{l}0.288 \\
0.018\end{array}$ & $\begin{array}{l}0.286 \\
0.012\end{array}$ & $\begin{array}{l}0.280 \\
0.010\end{array}$ & \pm \\
\hline
\end{tabular}

Notice: WT model: no treatment; WT moxibustion: a suspended moxibustion with a specially-made moxa stick for 20 min on L5-L6 segment; KO model: no treatment; KO moxibustion: a suspended moxibustion for $20 \mathrm{~min}$ on L5-L6 segment.

Compared with the WT model group, ${ }^{*} \mathrm{P}<0.05,{ }^{* *} \mathrm{P}<0.01$; compared with the KO model group, $\triangle \mathrm{P}<0.05, \triangle \Delta \mathrm{P}<0.01$.

Table 5: Comparisons of paw volumes of mice in wild-type groups and TRPV1 knockout groups.

\section{5}

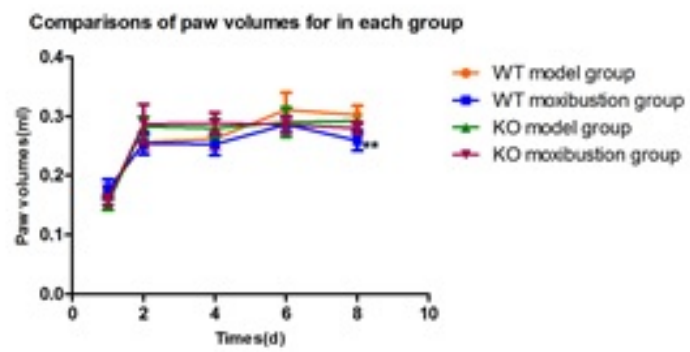

Figure 5: Data of inflammatory factors were presented as mean \pm SEM (WT: $\mathrm{n}=8, \mathrm{KO}: \mathrm{n}=7$ ) by histogram.

WT model group was of no treatment; WT moxibustion group was given a suspended moxibustion with a specially-made moxa stick for 20 min on L5-L6 segment; KO model group was of no treatment; KO moxibustion group was given a suspended moxibustion for $20 \mathrm{~min}$ on L5-L6 segment. Data of paw volumes were presented as mean \pm SEM (WT: $n=8, K O: n=7$ ) by curve graph.

\begin{tabular}{|l|l|l|l|l|}
\hline & $\begin{array}{l}\text { WT model } \\
\text { group }\end{array}$ & $\begin{array}{l}\text { WT mox } \\
\text { group }\end{array}$ & $\begin{array}{l}\text { Ko model } \\
\text { group }\end{array}$ & $\begin{array}{l}\text { Ko mox } \\
\text { group }\end{array}$ \\
\hline IL-1 $\beta$ & $82.93 \pm 3.39$ & $65.99 \pm 5.45^{* *}$ & $79.98 \pm 1.67$ & $75.44 \pm 2.05$ \\
\hline TNF- $\alpha$ & $58.63 \pm 1.96$ & $38.06 \pm 1.52^{* *}$ & $44.98 \pm 1.95$ & $44.39 \pm 2.01$ \\
\hline
\end{tabular}

Notice: WT model: no treatment; WT moxibustion: a suspended moxibustion with a specially-made moxa stick for 20 min on L5-L6 segment; KO model: no treatment; KO moxibustion: a suspended moxibustion for $20 \mathrm{~min}$ on L5-L6 segment. Compared with the WT model group, ${ }^{*} \mathrm{P}<0.05,{ }^{\star *} \mathrm{P}<0.01$; compared with the KO model group, ${ }^{\Delta P}<0.05,{ }^{\Delta} \mathrm{P}<0.01$.

Table 6: Comparisons of inflammatory factors of mice in wild-type groups and TRPV1 knockout groups.

\section{6}

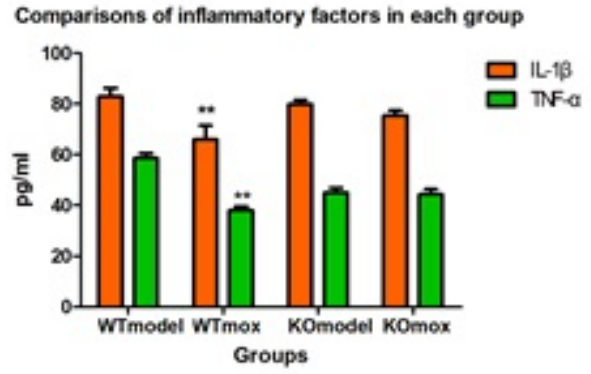

Figure 6: Significant differences compared with the WT model group: ${ }^{*} \mathrm{P}<0.05,{ }^{* *} \mathrm{P}<0.01$, and with the KO model group: ${ }^{\Delta} \mathrm{P}<0.05$, ${ }^{\Delta \Delta} \mathrm{P}<0.01$. WT model group was of no treatment; WT moxibustion group was given a suspended moxibustion with a specially-made moxa stick for 20 min on L5-L6 segment; KO model group was of no treatment; $\mathrm{KO}$ moxibustion group was given a suspended moxibustion for 20 min on L5-L6 segment. Data of paw volumes were presented as mean \pm SEM (WT: $n=8, K O: n=7$ ) by curve graph.

\section{Discussion}

TRPV1 has been shown to play a pivotal role in inflammatory conditions [6]. Therefore, TRPV1 is a promising target for development of inflammation [19].

AA was used as the animal model for the study. After $24 \mathrm{~h}$ by injection of FCA, mice appeared the acute inflammatory response, which was showed foot joint red and swollen AA and human RA have many similar clinlcal symptoms and dysimmunity, which is suitable for the study of peripheral inflammation.

TRPV1 played an important role in the progress of inflammation, which is the hub of almost all the inflammatory especially neuronal inflammatory signaling pathways. During tissue injury and inflammation, TRPV1 functions as a sensor of the detecting irritants by transmitting noxious stimuli to the central nervous system and inducing the release of a variety of pro-inflammatory neuropeptides (such as CGRP and Substance P) and regulating proinflammatory cytokines (such as IL-1 $\beta$ and TNF- $\alpha$ ) at the peripheral terminal [11], at the same time, regulating the release of anti-inflammatory cytokines (such as somatostatin) [12]. 
Moxibustion showed anti-inflammatory effects on mice with adjuvant arthritis. TRPV1 played an important role during the progress of treatments. In the first part of our experiment, on day 8 , compared with the model group, paw volumes in the capsaicin group and moxibustion group were significantly decreased $(\mathrm{P}<0.01)$; what's more, paw volumes of moxibustion group were much lower than that of capsaicin group. Tsuji et al. [20] found that application of TRPV1 agonist could suppress the generation of TNF- $\alpha$ and IL- $1 \beta$ as well as TNF- $\alpha$ and IL- $1 \beta$ mRNA expression, which is consisted with the results of serum TNF- $\alpha$ and IL-1 $\beta$ levels determined in our experiment.

Compared with the model group, capsaicin and moxibustion can both significantly reduce serum levels of IL- $1 \beta$ and TNF- $\alpha(P<0.01)$. In addition, compared with the capsaicin group, IL- $1 \beta$ and TNF- $\alpha$ levels of moxibustion group were much lower $(\mathrm{P}<0.01)$ (Table 2). Results mentioned above showed that, 1) moxibustion had an antiinflammatory effect. Studies have found that repeated or prolonged application of TRPV1 agonists capsaicin could induce antiinflammatory properties [21], while capsaicin and heat $>43^{\circ} \mathrm{C}$ may have a common molecular pathway [22]. Based on what's mentioned above, we propose that repeated application of heat stimulation produced by moxibustion could generate the same anti-inflammatory effect as capsaicin did. Schumacher [23] revealed several mechanisms of anti-inflammatory and analgesic effects of TRPV1 agonists that are overlapping and complementary, including desensitization, nociceptor dysfunction, neuropeptide depletion, and nerve terminal destruction. Among these mechanisms, dysfunction of nociceptive receptors may be the most important role in the effects of analgesia therapy 2).

The anti-inflammatory effect of moxibustion may be better than that of capsaicin. In our experiment, paw volumes as well as TNF-a and IL- $1 \beta$ levels of moxibustion group were both much lower than that of capsaicin group. In our experiment, paw volumes as well as TNF-a and IL- $1 \beta$ levels of moxibustion group were both much lower than capsaicine group. The anti-inflammatory effect of capsaicin is dosedependent [24] and the dose we administrated in the experiment may be too low to exhibit the anti-inflammatory effect of moxibustion was better than that of capsaicin.

The anti-inflammatory effects disappeared if TRPV1 antagonist was applied during moxibustion. During the second part of our experiment, we explored the effect of moxibustion on adjuvant arthritis after pretreatment by capsazepine. Some studies had demonstrated the effect of capsaicin could be completely blocked by TRPV1 antagonist capsazepine [25], so we did not set up capsaicin +capsazepine group in our experiment. Results of paw volumes showed that, on day 8 , compared with model group, the paw volumes of moxibustion group, $\mathrm{MC}$ group and capsazepine group were significantly decreased $(\mathrm{P}<0.01)$, which suggested all moxibustion, capsazepine and $\mathrm{MC}$ group had the effect of reducing paw volumes.

MC group and moxibustion group were significantly different $(\mathrm{P}<0.05)$, and the paw volumes of MC group were higher than moxibustion group, prompting capsazepine might partly antagonized the effects of moxibustion (Table 3). The results of inflammatory factors IL- $1 \beta$ and TNF- $\alpha$ level showed consistent outcomes. The IL-1 $\beta$ and TNF- $\alpha$ levels of MC group was far lower than that of model group $(\mathrm{P}<0.01)$, but higher than moxibustion $(\mathrm{P}<0.01)$ and capsazepine group $(\mathrm{P}<0.01)$ (Table 4$)$. The anti-inflammatory effect of moxibustion was slightly decreased by the pretreatment with capsazepine. Mcintyre Peter's [26] animal experiments and Istvan Nagy's [27] cell experiments both revealed that capsazepine was just a weak inhibitor of the heat response mediated by TRPV1 receptor, and this conclusion also supports our results. All the results indicate that TRPV1 was participated in the anti-inflammatory effect of moxibustion.

The anti-inflammatory effects disappeared too on TRPV1 knockout mice. To further confirm the anti-inflammatory effect of moxibustion was mediated by TRPV1, we used wildtype C57BL/6 mice and TRPV1 knockout mice for the third part of the experiments. Results of paw volumes showed that, on day 8 , compared with WT model group, paw volumes in WT moxibustion group were significantly decreased $(\mathrm{P}<0.01)$, while $\mathrm{KO}$ moxibustion group and $\mathrm{KO}$ model group had no difference $(P>0.05)$ (Table 5). Serum levels of IL-1 $\beta$ and TNF- $\alpha$ also reflected the WT moxibustion group and WT model group were significantly different $(\mathrm{P}<0.01)$; yet $\mathrm{KO}$ moxibustion group and $\mathrm{KO}$ model group were not $(\mathrm{P}>0.05)$.

TRPV1 itself is a heat sensor [22], TRPV1 knockout mice exhibited reduced thermal nociception [28], which showed that TRPV1 was necessary for reactions to noxious thermal stimuli [29]. Therefore, there was no difference between the $\mathrm{KO}$ model group and $\mathrm{KO}$ moxibustion group in our experiments, suggesting that antiinflammatory effect of moxibustion was TRPV1-mediated, in other words, moxibustion would lose its anti-inflammatory effect if lacking TRPV1. In addition, the TRPV1-deficient mice showed impaired responses to noxious thermal stimuli only over $50^{\circ} \mathrm{C}$ [22], and the peak value of skin temperature was only $45.2^{\circ} \mathrm{C} \sim 45.5^{\circ} \mathrm{C}$ [5] during moxibustion, which could partly explain why there were no significant difference between $\mathrm{KO}$ moxibustion group and $\mathrm{KO}$ model group.

Sato A found that acupuncture-like stimulation can regulate various visceral functions by reflex responses, which had the segmental features via studying the neuromechanism of regulating effects of acupuncture-like stimulation on visceral functions [30]. In addition, there were studies showed that the muscles and skin of the lower limbs were controlled by nerve segments of L4 S2 spinal cord and the stimulation on the Houhui" points located on the inside of parapophysis of sixth lumbar could regulate the lower limb functions. Kelly's animal experiments [18] also revealed that ligation of L5 and L6 spinal nerve would result in partial deafferentation of the hindpaw. The researches mentioned above suggested that segmental innervations was one of the rules of how acupuncture functioned [31], according to which, we selected the area of L5 and L6 spinal cords as the point for moxibustion and capsaicin injection.

During the inflammation, the sensibilization of TRPV1 promotes the inflammatory hyperpathia [32]. A number of studies had proved that TRPV1 antagonists could increase the noxious heat pain threshold [33] and inhibit thermal hyperalgesia [34] by suppressing the expression of TRPV1 and so that it showed the anti-inflammatory effect in different inflammatory and neuropathic pain models [35]. Repeated or prolonged application of TRPV1 agonists also showed anti-inflammatory effect.

In vivo inflammatory disorders, TRPV1 agonists may play a role of anti-inflammatory and immunoregulation [20]. The inflammatory responses induced by TNF- $\alpha$ could be lightened via TRPV1 agonists, but aggravated by TRPV1 antagonists [36]. It had been proved that repeated capsaicin application to the skin produces a degeneration of epidermal nerve fibers [37] that may underlie the effects of TRPV1 agonists. Schumacher considered that nerve terminal destruction may be the most important role in the effects of anti-inflammatory and analgesia therapy [23]. 
The thermal stimulation is the most important determination of the therapeutic efficacy of moxibustion. Temperature plays a critical role in the effect of moxibustion therapy. The temperature produced by moxibustion ranges from $34^{\circ} \mathrm{C}$ to $57^{\circ} \mathrm{C}$, consistent with the thermal activation thresholds of TRPV1-4. The peak value of skin temperature ranged from $45.2^{\circ} \mathrm{C}$ to $45.5^{\circ} \mathrm{C}$ in suspended moxibustion. In addition, synthesizing the former results of our research team, we kept the distance between the skin and the moxa stick of $10 \pm 2 \mathrm{~mm}$, so that the temperature was stabilized at $46 \pm 1^{\circ} \mathrm{C}$. A certain quantity (amount) of moxibustion is the basic guarantee of efficacy, it is common to increase moxibustion quantity to improve the curative effect in clinical.

The essence of various methods of moxibustion therapy is to achieve a certain intensity of thermal stimulation via space (area or distance) to reach the amount required in the treatment through the extension along the time axis. Accumulated times of treatment are able to increase moxibustion intensity of a single treatment, with constant temperature and area. During the experiment, we applied moxibustion 10 minutes a day for 7 days, accumulating the number of days to achieve the anti-inflammatory effect, just like the repeated application of capsaicin.

Expression of TRPV1 up-regulates in the inflammatory conditions. The therapy of anti-inflammation mediated by TRPV 1 has been widely used in clinical practice. The anti-inflammation therapeutic effect of TRPV1 antagonist is mainly depending on suppressing TRPV1 expression. Application of TRPV1 agonist capsaicin in antiinflammation currently has been presented in the circulatory system and kidney disease [38], autoimmune disease, inflammatory bowel disease [15] and so on.

However, both agonists and antagonists have inevitable side effects. Capsaicin can't be administered systemically because of its adverse effects, such as a burning sensation and Bezold-Jarisch reflex in the initial phase of bradycardia and hypopnea [35]. Likewise, the usage of TRPV1 antagonists can induce the risk of accidental burns [3], causing scald [33], meanwhile the anti-inflammatory role of TRPV1 by potent antagonists may lead to aggravation of the disease [12]. Heat stimulation of moxibustion exerts its TRPV1-mediated antiinflammatory effect in the local place through the neuroimmunoendocrinology network, which has a great advantage of safety and no side effects.

\section{Conclusions}

TRPV1 is the target of anti-inflammatory and analgesic therapy. The TRPV1 antagonists (such as capsazepine) exert theirs antiinflammatory effect via suppressing the TRPV1 expression, while repeated application of TRPV1 pharmacologic agonists (such as capsaicin) via producing a destruction or desensitization in the terminal of nociceptive receptors. As one of the physical agonists of TRPV1, heat stimulation of moxibustion exerts its TRPV1- mediated anti-inflammatory effect. TRPV1 plays a important role in the antiinflammatory effect of moxibustion. Without the mediation of TRPV1, moxibustion lost its anti-inflammatory effect.

\section{Acknowledgment}

The paper was supported by National key basic research program 973 (no. 2011CB505206), 2013 Jiangsu Province Education Department of Natural Science Research of major projects (no. 13KJA360001), Academic propagate project on scientific and technical innovation team, Nanjing University of Chinese Medicine 2013 scientific and technical innovation team project. JFJ designed the study. JJL and YJcarried out the animal experiments, XJW participated in the serum IL- $1 \beta$ and TNF- $\alpha$ level decetion by ELISA. JJL performed the statistical analysis and drafted the manuscript. All authors read and approved the final manuscript.

\section{References}

1. Jiang JF, Wang LL, Bin X, Ling H, Song XG, et al. (2013) [Antiinflammatory: effect mechanism of warming-dredging in moxibustion]. Zhongguo Zhen Jiu 33: 860-864.

2. Wang GY, Wang LL, Xu B, Zhang JB, Jiang JF (2013) Effects of Moxibustion Temperature on Blood Cholesterol Level in a Mice Model of Acute Hyperlipidemia: Role of TRPV1. Evid Based Complement Alternat Med 2013: 871704

3. Surowy CS, Neelands TR, Bianchi BR, McGaraughty S, Kouhen REI (2008) " (R)- (5-tert-butyl-2,3-dihydro-1H-inden-1-yl)-3- (1H-indazol-4yl)-urea (ABT-102) blocks polymodal activation of transient receptor potential vanilloid 1 receptors in vitro and heat-evoked firing of spinal dorsal horn neurons in vivo". J PHARMACOL EXP THER 326: 879-888

4. Vay L, Gu C, McNaughton PA (2012) The thermo-TRP ion channel family: properties and therapeutic implications. Br J Pharmacol 165: 787-801.

5. Dong XM, Dong QS, Xian MQ, Zheng XL, Zhang SH (1999) Observation on comparison of effects of different moxibustion to acupoint temperature. Chinese Acupuncture \& Moxibustion: 22-26

6. Sooampon S, Phoolcharoen W, Pavasant P (2013) Thermal stimulation of TRPV1 up-regulates TNF $\alpha$ expression in human periodontal ligament cells. Arch Oral Biol 58: 887-895.

7. Li WG, Tu Q, Gu XJ (2010) [Effect on content of serum inflammatory cytokines of patients with ankylosing spondylitis in early stage treated by long snake moxibustion at Governor Vessel and functional exercise]. Zhongguo Zhen Jiu 30: 200-202.

8. Lin YP, Feng YS, Shi DM, Hou YL (2013) Effect of Moxibustion treatment on the level of cytokine in gastric tissue homogenate of the rats with $\mathrm{Hp}$ gastritis. Chinese Journal of Immunology 29: 900-909

9. Ji MY, Wang LL, Jiang JF, Zhou XY, Ma MY (2013) Effect of warming moxibustion on oxidative stress-inflmmatory response in rats with hyperlipemia. China Journal of Traditional Chinese Medicine and Pharmacy 28: 2301-2304

10. Yang HQ, Liu XG, Yang X, Chen T, Yu SG (2013) [Effect of different types of moxibustion intervention on expression of inflammatory cytokines IL-1 and TNF-alpha in rabbits with rheumatoid arthritis]. Zhen Ci Yan Jiu 38: 134-139.

11. Couto M, de Diego A, Perpiñi M, Delgado L, Moreira A (2013) Cough reflex testing with inhaled capsaicin and TRPV1 activation in asthma and comorbid conditions. J Investig Allergol Clin Immunol 23: 289-301.

12. Devesa I, Planells-Cases R, Fernández-Ballester G, González-Ros JM, Ferrer-Montiel A (2011) "Role of the transient receptor potential vanilloid 1 in inflammation and sepsis". Journal of Inflammation Research 4: 67-81

13. Fernandes ES, Liang L, Smillie SJ, Kaiser F, Purcell R (2012) TRPV1 Deletion Enhances Local Inflammation and Accelerates the Onset of Systemic Inflammatory Response Syndrome. The Journal of Immunology 188: 5741-5751

14. Bishnoi M, Bosgraaf CA, Abooj M, Zhong LL, Premkumar LS (2011) Streptozotocin-Induced Early Thermal Hyperalgesia is independent of Glycemic State of Rats: Role of Transient Receptor Potential Vanilloid 1 (TRPV1) and Inflammatory mediators. MOL PAIN 7: 52

15. Kobayashi M, Watanabe K, Yokoyama S, Matsumoto C, Hirata M, et al. (2012) Capsaicin, a TRPV1 Ligand, Suppresses Bone Resorption by Inhibiting the Prostaglandin E Production of Osteoblasts, and Attenuates the Inflammatory Bone Loss Induced by Lipopolysaccharide. ISRN Pharmacol 2012: 439860. 
Citation: Li JJ, Jiang JF, Jiang Y, Wu X (2015) Anti-Inflammatory Effects of Moxibustion on Mice with Adjuvant Arthritis: Role of TRPV1. Altern Integr Med 4: 199. doi:10.4172/2327-5162.1000199

Page 8 of 8

16. Wang JF, Zhou Y, Liu JH, Lu JQ, Ge LJ, et al. (2006) Guidance Suggestions for the Care and Use of Laboratory Animals. The Ministry of Science and Technology of the People's Republic of China.

17. Nguyen TL, Nam YS, Lee SY, Kim HC, Jang CG (2010) Effects of capsazepine, a transient receptor potential vanilloid type 1 antagonist, on morphine-induced antinociception, tolerance, and dependence in mice. BRIT J ANAESTH 105: 668-674

18. Kelly S, Chapman V (2002) Effects of peripheral nerve injury on functional spinal VR1 receptors. Neuroreport 13: 1147-1150.

19. Lee JY, Shin TJ, Choi JM, Seo KS, Kim HJ, et al. (2013) Antinociceptive curcuminoid, KMS4034, effects on inflammatory and neuropathic pain likely via modulating TRPV1 in mice. Br J Anaesth 111: 667-672.

20. Tsuji F, Murai M, Oki K, Seki I, Ueda K, et al. (2010) Transient receptor potential vanilloid 1 agonists as candidates for anti-inflammatory and immunomodulatory agents. Eur J Pharmacol 627: 332-339.

21. Shin YH, Namkoong E, Choi S, Bae JS, Jin M, et al. (2013) Capsaicin regulates the NF- $\mathrm{kB}$ pathway in salivary gland inflammation. J Dent Res 92: 547-552.

22. Tominaga M, Caterina MJ (2004) Thermosensation and pain. J Neurobio 61: 3-12.

23. Schumacher MA (2010) Transient receptor potential channels in pain and inflammation: therapeutic opportunities. Pain Pract 10: 185-200.

24. O'Neill J, Brock C, Olesen AE, Andresen T, Nilsson M, et al. (2012) Unravelling the mystery of capsaicin: a tool to understand and treat pain. Pharmacol Rev 64: 939-971.

25. Kwak J (2012) Capsaicin Blocks the Hyperpolarization-Activated Inward Currents via TRPV1 in the Rat Dorsal Root Ganglion Neurons. Exp Neurobiol 21: 75-82.

26. McIntyre P, McLatchie LM, Chambers A, Phillips E, Clarke M, et al. (2001) Pharmacological differences between the human and rat vanilloid receptor 1 (VR1). Br J Pharmacol 132: 1084-1094.

27. Nagy I, Rang HP (1999) Similarities and differences between the responses of rat sensory neurons to noxious heat and capsaicin. J Neurosci 19: 10647-10655.

28. Cui M, Honore P, Zhong C, Gauvin D, Mikusa J, et al. (2006) TRPV1 receptors in the CNS play a key role in broad-spectrum analgesia of TRPV1 antagonists. J Neurosci 26: 9385-9393.
29. Asai H, Ozaki N, Shinoda M, Nagamine K, Tohnai I, et al. (2005) Heat and mechanical hyperalgesia in mice model of cancer pain. Pain 117: 19-29.

30. Sato A, Sato Y, Uchida S (2002) Reflex modulation of visceral functions by acupuncture-like stimulation in anesthetized rats. International Congress Series 1238: 111-123

31. Zhang Y, Yu Y, Meng Q, Li J (2011) Effects of electro-aupuncturing different neurosegmental acu-points on intragastric pressure of gastric motility abnormalities in rats. Journal of TCM Univ? of Hunan 31: 65-68

32. Vetter I, Cheng W, Peiris M, Wyse BD, Roberts-Thomson SJ (2008) Rapid, Opioid-sensitive Mechanisms Involved in Transient Receptor Potential Vanilloid 1 Sensitization. The Journal Of Biological Chemistry 283: 19540-19550

33. Brederson JD, Kym PR, Szallasi A (2013) Targeting TRP channels for pain relief. Eur J Pharmacol 716: 61-76.

34. Urano H, Ara T, Fujinami Y, Hiraoka BY (2012) Aberrant TRPV1 expression in heat hyperalgesia associated with trigeminal neuropathic pain. Int J Med Sci 9: 690-697.

35. Watabiki T, Kiso T, Kuramochi T, Yonezawa K, Tsuji N (2011) Amelioration of Neuropathic Pain by Novel Transient Receptor Potential Vanilloid 1 Antagonist AS1928370 in Rats without Hyperthermic Effect. The Journal Of Pharmacology And Experimental Therapeutics 336: 743-750

36. Zhao JF, Ching LC, Kou YR, Lin SJ, Wei J, et al. (2013) Activation of TRPV1 prevents OxLDL-induced lipid accumulation and TNF- $\alpha$-induced inflammation in macrophages: role of liver $\mathrm{X}$ receptor $\alpha$. Mediators Inflamm 2013: 925171.

37. Vyklický L, Nováková-Toušová K, Benedikt J, Samad A, Touška F (2008) Calcium-Dependent Desensitization of Vanillo id Receptor TRPV1: A Mechanism Possibly Involved in Analgesia Induced by Topical Application of Capsaicin. PHYSIOL RES 57: 59-68

38. Tsuji F, Aono H (2012) Role of transient receptor potential vanilloid 1 in inflammation and autoimmune diseases. Pharmaceuticals (Basel) 5: 837-852. 